\title{
Adhesion to Gold: A Review
}

\section{J. Cognard}

Asulab S.A., Passage Max-meuron 6, CH-2001 Neuchâtel, Switzerland

The adhesion of substances to gold, and our understanding of it, is of potential industrial importance in a number of diverse fields such as heat transfer surfaces and jewellery manufacture.

Adhesion is a complex subject and is not fully understood as yet. This explains the many different approaches followed in the field. For instance, in physics we calculate the ideal strength (1) and from a mechanics approach the force of adherence (2), while physical chemists try to understand the molecular interactions which are responsible for the adhesion (3).

In the first part of this review the more important results obtained from these approaches will be discussed. These results will relate the force of adherence to the energy of adhesion or the substrate surface tension. The middle section is devoted to surface tension on gold and the controversial matter of whether or not gold is wettable. Recent findings on gold wettability will be discussed and it will be shown that contamination by hydrocarbons is not directly related to the apparent hydrophobicity of the metal. The final part of the article discusses experimental results on the strength of adhesive joints between gold surfaces under various stresses.

The review concludes with a presentation of the view that slow superficial reconstruction of gold surfaces may be an important reason for the apparent discrepancies in their behaviour which have been recorded.

Discussion of the various approaches is of necessity somewhat mathematical. The detail has, however, been kept to a minimum and interested readers should consult the references quoted for a fuller treatment. A glossary of terms used has been compiled to assist those readers less conversant with the subject to follow the arguments presented in this article.

\section{The Physics of Adhesion}

In considering adhesion from a physical point of view we attempt to discover how the force (or energy) necessary to separate a solid body into two partscan be calculated, from a knowledge of the bulk and surface properties. The solutions derived give the ideal adhesion, as discussed below:

\section{The Thermodynamic Solution (Ideal Adhesion)}

Adamson (1) defines the ideal adhesion as 'the adhesion expected under one or another model situation', and some models and their corresponding solutions will be considered below. The first could be called the thermodynamic approach as it considers the reversible work of adhesion. In this case the energy required to separate the two parts is equal to the enetgy necessary to assemble them.

\section{Breaking a Solid}

In the process of breaking a solid, two new surfaces of energy $\gamma_{s}^{*}$ are created. The energy required is $W$;
$\mathrm{W}=2 \gamma_{\mathrm{s}}$

$2 \gamma_{s}$ is the cohesive energy, $W_{f}$, of the solid, and is equal to the work done against the cohesive forces, $F_{c}$, over the effective range of atomic distance, $a$, during the breaking process:

$$
W_{c}=F_{c} \cdot a \cdot A
$$

Thus in this model the energy required to break the solid is equated with the cohesive energy $W_{c}$ and the corresponding force is $F_{c}$. This could be the case during the breaking of a brittle solid or the cohesive rupture of an adhesive bond.

\section{Breaking an Interface}

Two bodies, $A$ and $B$, in intimate contact form an interface of surface free energy $\gamma_{A B}$. In the process of breaking two new surfaces of energy $\gamma_{A}$ and $\gamma_{B}$ are created. The required energy is the difference between those of the final and initial states as shown in the Dupré equation:

$$
\mathrm{W}_{\mathrm{a}}=\gamma_{\mathrm{A}}+\gamma_{\mathrm{B}}-\gamma_{\mathrm{AB}}
$$

$W_{d}$ is a thermodynamic value known as the energy of adhesion, and this energy should be the work of the force of adhesion, $F_{a}$, over the range of atomic interactions. However $F_{a}$ is not experimentally accessible. This solution could be applied to the interfacial rupture of adhesive joints.

In fact, both these thermodynamic models give values much higher than those obtained by experiment. This anomaly has led to the mechanical approach.

\section{The Mechanics of Adhesion (2) \\ The Rupture of a Rigid Body}

In this approach one considers that the force of adhesion is not measurable and that it is always the force of separation which is measured. In this process the solid does not only separate but also deforms. Rupture occurs when the elastic energy, $U_{E}$, is equal to the surface energy, $2 \gamma_{s}$, generated during rupture. If we hypothesise that deformation occurs in the elastic domain of the solid, the Young's modulus of which is $E$, we can write

$$
\mathrm{U}_{\mathrm{E}}=\frac{\sigma^{2}}{\mathrm{E}} \cdot \frac{\mathrm{a}}{2}
$$

and the Orowan equation

$$
\sigma=\left[\frac{\gamma_{s} \mathrm{E}}{\mathrm{a}}\right]^{1 / 2}
$$

\footnotetext{
* In this review all energies are referred to the unit of surface $A$. The relation between the force $F$ and the stress is $=\frac{F}{A}$ for surface $A$.
} 


\author{
Cobesive Energy: \\ Cobesive Rupture: \\ Critical Surface \\ Tension: \\ Dispersive Energy of \\ Adhesion: \\ Dispersive Surface \\ Energy: \\ Energy of Adbesion: \\ Force of Adherence: \\ Force of Adhesion: \\ Force of Cohesion: \\ Hydropbobic Surface: \\ Ideal Adbesion: \\ Ideal Strength: \\ Interfacial Rupture: \\ Maximum Stress \\ at Break: \\ Polar Energy of \\ Adbesion: \\ Polar Surface Energy: \\ Stress: \\ Surface Free Energy: \\ Surface Tension:
}

Glossary of Terms Used

Reversible work of the atomic forces, $F_{c}$, over the range of atomic interaction, $a,\left(W_{c}=F_{c}, a\right)$

Rupture of an adhesive bond, within the adhesive

The value of $\gamma_{s}$ for which $\cos \theta=1\left(\gamma_{c}\right)$ generally obtained by extrapolation of a plot of $\theta$ vs $\gamma_{L}$ for

liquids of various $\gamma_{L}$ (see Zisman (18))

That part of the energy of adhesion due to dispersive interactions $\left(W_{a}^{d}\right)$

That part of the surface energy due to dispersive interactions $\left(\gamma_{s}^{d}\right)$

The reversible work necessary to separate two bodies $\left(W_{a}\right)$

The experimental value of the force which leaves a crack in equilibrium $(F)$

The force of attraction of two perfect solid bodies toward one another $\left(F_{d}\right)$

Atomic forces between bulk atoms in a solid state $\left(F_{c}\right)$

$A$ low energy surface on which water does not spread and forms a drop. Also (electrochemical definition), a surface that does not orientate water dipoles (converse is bydropbilic)

The adhesion expected for a given model

The system strength necessary to separate a rigid, perfect solid

Rupture of a joint occurring at the interface between the solid and the adhesive

The experimental force required to break an assembly $\left(\sigma_{\mathrm{B}}\right)$

The difference between the energy of adhesion and the dispersive energy of adhesion $\left(W_{a}^{D}\right)$

The difference between the surface energy and the dispersive surface energy $\left(\gamma_{s}\right)$

Pulling force per surface unit $(\sigma)$

The energy of the solid unit surface $\left(\gamma_{s}\right)$

The energy of a liquid unit surface $\left(\gamma_{L}\right)$
Thissolution also gives values higher than the experimental one and led Griffith (4) to consider that solids do not break as rigid bodies.

\section{The Brittle Fracture of Real Solids}

Real solids are not perfect and contain defects. Breaking occurs through the concentration of elastic energy around flaws. The stress necessary to transform a flaw of length $c$ into a crack that propagates is given by the Griffith equation:

$$
\sigma=\frac{F}{A}=\left[\frac{\gamma_{s} \cdot E}{c}\right]^{1 / 2}
$$

Flaws of dimensions $10^{4}$ to $10^{5} \AA$ yield data which correspond to experimental values.

\section{The Rupture of Visco-Elastic Solids: the Force of 'Adherence'}

An experimental device is a system comprised of the joint and its load. The total energy $U_{T}$ of that system is the sum of the elastic, $U_{B}$, potential, $U_{p}$, and surface, $U_{s}$, energies. At equilibrium, the energy of the system is at a minimum and

$$
\mathrm{dU}_{\mathrm{T}}=\mathrm{dU}_{\mathrm{E}}+\mathrm{dU}_{\mathrm{p}}+\mathrm{dU}_{\mathrm{s}}=0
$$

and as

$$
\mathrm{dU}_{s}=-\mathrm{W}_{\mathrm{a}} \mathrm{d} A
$$

equation 7 yields

$$
\mathrm{dU}_{\mathrm{T}}=\left(\mathrm{G}-\mathrm{W}_{\mathrm{a}}\right) \mathrm{dA}
$$

which defines the strain energy release rate, $G$, as

$$
\mathrm{G}=\frac{\mathrm{dU}_{\mathrm{E}}}{\mathrm{dA}}+\frac{\mathrm{dU}_{\mathrm{p}}}{\mathrm{dA}}
$$

The propagation of a fracture within a viscoelastic solid is promoted by the difference in magnitude of the strain energy release rate, $G$, and the surface energy $W_{a}$, Equilibrium under a load is defined by

$$
\mathrm{G}=\mathrm{W}_{\mathrm{a}}
$$

The sign of $\frac{d G}{d A}$ determines the stability of the equilibrium, and a negative value indicates that the crack will propagate. Maugis(2) proposed that 'adherence force' be called that force just necessary to cause the separation under the given experimental conditions, in which case $\frac{d G}{d A}=0$.

\section{The Force of Adherence of an Adhesive Joint}

Initially, let us consider a liquid joint and attempt to extend the result to a solid adhesive. The insertion of a liquid, $L$, between two solids leads to a high adhesion force, $F$, which is a function of the separation speed, $v,(2,5)$. The required force includes the energy of adhesion plus the viscoelastic dissipation of energy which is a function, $f(t)$, of the time, $t$,

$$
F=\frac{A \cdot W_{3}}{h}+f(t)
$$

$h$ being the liquid thickness. 
For instance, in the case of two discs of radius $R$ equation 12 yields (2)

$$
\mathrm{F}=\frac{2 \pi \mathrm{R}^{2} \gamma_{1} \cos \theta}{\mathrm{h}}+\frac{3 \pi \eta \mathrm{R}^{4}}{4 \mathrm{~h}^{2}} \cdot \frac{1}{\mathrm{t}}
$$

$\gamma_{L}$ being the liquid surface tension and $\eta$ the viscosity of the liquid.

In the case of a polymeric adhesive the viscous term, $f(t)$, is, in general, unknown and equation 11 is written as

$$
\mathrm{G}=\mathrm{W}_{\mathrm{s}}=\mathrm{W}_{\mathrm{a}}+\mathrm{F}_{\text {visc }}
$$

where $W_{s}$ is an apparent energy of adhesion and $F_{p i s c}$ represents the viscoelastic dissipation of energy. Actually a joint will sustain astress only as long as the interface will support it and equation 11 may be written $(5,6,7)$ :

$$
\mathrm{G}-\mathrm{W}_{\mathrm{a}}=\mathrm{W}_{\mathrm{a}} \mathrm{f}(\mathrm{v}, \mathrm{t}, \mathrm{T})
$$

In the case of peeling, equation 14 is written $(4,5)$

$$
\mathrm{W}_{\mathrm{s}}=\mathrm{g}(\mathrm{v}, \mathrm{t}, \mathrm{T}) \mathrm{W}_{\mathrm{a}}
$$

where the functions $f$ or $g$ are characteristic of the adhesive and $\nu$ is the speed of propagation of the crack, $t$ represents the time and $T$ the temperature.

Each of the solutions obtained from one or another model show that the joint strength is related through the energy of adhesion eventually to the solid surface tension.

Results of calculations (8) of the relation between the maximum strength at breaking or the peel force, and the energy of adhesion are illustrated in Figure 1 for some classical situations. Even where the function $f(v, t, T)$ is unknown the knowledge of the energy of adhesion should permit comparison of different joints formed with various substrates and the same adhesive.

It is the goal of the physical chemistry approach to relate surface energy and the energy of adhesion.

\section{Physical Chemistry of Adhesion \\ Adhesion of a Liquid to a Solid}

A drop of liquid, $\mathbf{L}$, deposited on a solid surface of energy $\gamma_{s}$ will either spread or form a spherical segment. The spreading condition is (1):

$$
\mathrm{W}_{\mathrm{a}}-2 \gamma_{\mathrm{L}}>0
$$

Water spreads over hydrophilic surfaces which are normally clean surfaces of high surface energy such as metals and ionic compounds. Those surfaces over which water fails to spread are termed hydrophobic.

The contact angle, $\theta$, of a liquid of surface tension, $\gamma_{1}$, with a solid of surface energy, $\gamma_{s}$ is given by the Young-Dupré equation:
Fig. 1. Relation of the breaking stress $\gamma_{B}$ or the peel strength, $P$, to the energy of adherence $W_{3}$ of joints under tensile shear or peel stress
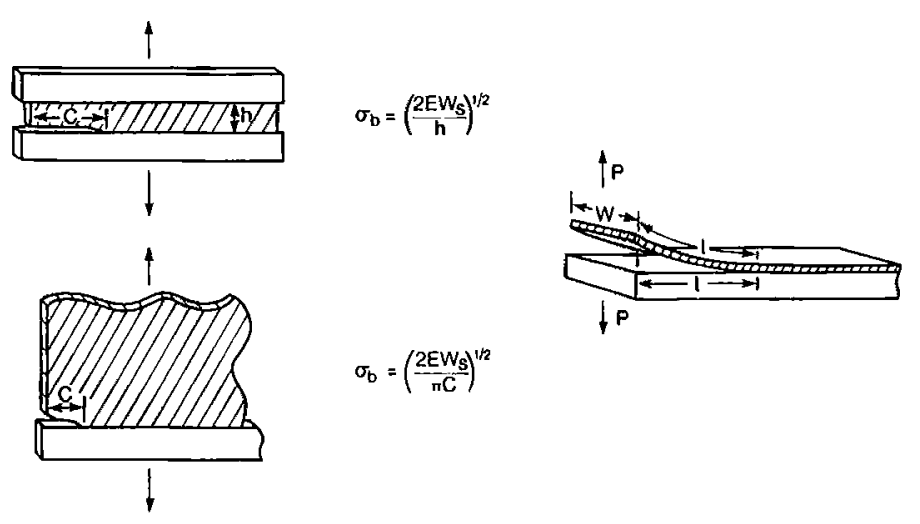

$W_{S}=\frac{P l^{2}}{2 E I W}$

$$
\sigma_{\mathrm{b}}=\left(\frac{2 E W_{\mathrm{S}}}{\pi \mathrm{C}}\right)^{1 / 2}
$$
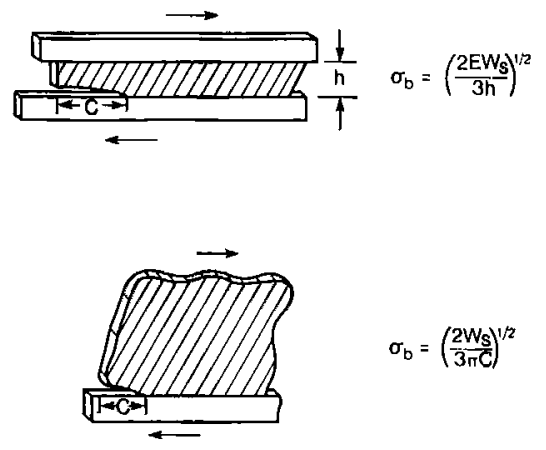

$$
\sigma_{b}=\left(\frac{2 W_{s}}{3 \pi C}\right)^{1 / 2}
$$

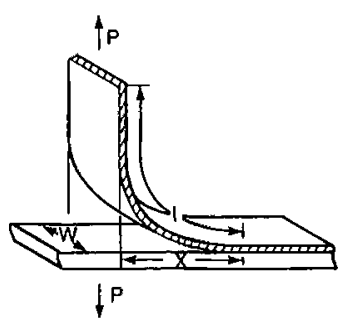

$w_{s}=\frac{p}{w}$ 


$$
\gamma_{\mathrm{s}}-\gamma_{\mathrm{sL}}=\gamma_{\mathrm{L}} \operatorname{Cos} \theta
$$

$\gamma_{s L}$ being the interfacial energy. From 3 and 18 the energy of adhesion, $W_{q}$, is related to $\gamma_{L}$ by:

$$
\mathrm{W}_{\mathrm{a}}=\gamma_{\mathrm{L}}(1+\operatorname{Cos} \theta)
$$

As both $\gamma_{L}$ and $\theta$ are measurable, equation 19 yields $W_{a}$ which is related to the joint strength through equation 14.

The Dispersive and Polar Contributions to the Energy of Adhesion

Atoms have either strong (metallic, ionic or covalent) or weak (van der Waals) dispersive interactions. In the interface between either metals or inorganic solids, with either an organic liquid or an organic polymer as adhesive, interactions are essentially dispersive.

Thus, it has been proposed (9) that the surface energy $\gamma_{s}$ should be written as the sum of two terms: one, $\gamma_{s}^{\mathrm{d}}$, representing the energy due to dispersive interaction, the other, $\gamma_{s}^{p}$, that due to polar (non dispersive) interactions:

$$
\gamma_{s}=\gamma_{s}^{\mathrm{d}}+\gamma_{s}^{\mathrm{p}}
$$

This leads to the expression of the energy of adhesion $W_{a}$ in two terms, dispersive $\left(W_{a}^{d}\right)$ and polar $\left(W_{a}^{p}\right)$ (non dispersive)

$$
\mathrm{W}_{\mathrm{a}}=\mathrm{W}_{\mathrm{a}}^{\mathrm{d}}+\mathrm{W}_{\mathrm{a}}^{\mathrm{p}}
$$

The Dispersive Part of the Energy of Adhesion

Although different mathematical expressions have been proposed, it seems to be currently accepted that the dispersive energy of interaction be expressed as the geometric mean of the dispersive surface energies of the two bodies ( $A$ and $\mathbf{B}$ ) in contact (9) viz.

$$
W_{a}^{d}=2\left(\gamma_{A}^{d}+\gamma_{B}^{d}\right)^{1 / 2}
$$

Apolar liquids, such as alkanes, of surface tension in the range 16 to $30 \mathrm{~mJ} / \mathrm{m}^{2}$ give only dispersive interactions. Highly polarizable liquids such as methylene iodide $\left(\gamma_{L}=\gamma_{L}^{l}=50.8 \mathrm{~mJ} / \mathrm{m}^{2}\right)$ or bromonaphthalene $\left(\gamma_{L}=\gamma_{L}^{\prime}=44.6 \mathrm{~mJ} / \mathrm{m}^{2}\right)$, are also essentially dispersive and used as test liquids to determine $\gamma_{s}^{l}$ of a given solid, $\mathrm{S}$, from the value of the contact angle $\theta$ of the test liquid through the combination of equations 14 and 17 .

\section{Polar Interactions}

Whereas the quantitative expression of the dispersive interactions seems to be well established, that of polar interaction is more controversial. Kaeble (10) proposed that $W_{a}$ is also the geometric mean of $\gamma_{A}^{p}$ and $\gamma_{B}^{p}$

Table I

The Surface Tensions of Liquid Gold

\begin{tabular}{c|c|c}
\hline $\begin{array}{c}\text { Temperature, } \\
{ }^{\circ} \mathrm{C}\end{array}$ & Atmosphere & $\begin{array}{c}\gamma_{\mathrm{Au}}^{\mathrm{L}}, \\
\mathrm{mJ} / \mathrm{m}^{2}\end{array}$ \\
\hline 1108 & Argon & $1130_{ \pm 10}$ \\
1200 & Helium & 1070 \\
1300 & Helium & 1020
\end{tabular}

$$
\mathrm{W}_{\mathrm{a}}=2\left(\gamma_{\mathrm{A}}^{\mathrm{p}} \cdot \gamma_{\mathrm{B}}^{\mathrm{p}}\right)^{1 / 2}
$$

but although widely used, this expression does not agree very well with experimental results.

Fowkes (11) suggests that polar interactions are essentially due to acid-base interactions and may be quantitatively expressed from Drago's acidity constants, $C$ and $E$, as

$$
\mathrm{W}_{\mathrm{a}}^{\mathrm{p}}=\mathrm{C}_{\mathrm{A}} \mathrm{C}_{\mathrm{B}}+\mathrm{E}_{\mathrm{A}} \mathrm{E}_{\mathrm{B}}
$$

Confirmation of this is awaited from further work on the determination of these constants.

\section{Application to Gold}

As gold does not form superficial oxides, there should be no acidbase interactions and determination of $\gamma_{A u}^{d}$ should lead to the description of its behaviour toward organic liquids and adhesives. The energy of adhesion to gold of an adhesive of surface tension $\gamma_{a d b}$ will be:

and

$$
\begin{gathered}
W_{a}=\gamma_{a d b}(1+\cos \theta) \\
W_{a} \sim W_{a}^{d}=2\left[\gamma_{\Delta \mathrm{u}}^{\mathrm{d}} \cdot \gamma_{a d d b}^{d}\right]^{1 / 2}
\end{gathered}
$$

The energy of rupture $W_{s}$ of the corresponding joint will be $W_{s}=\sigma_{\mathrm{B}} \cdot a=g \cdot W_{d}^{d}$ with $g \sim 50$ to 1000 , and $\sigma_{B}$ being the stress at the rupture.

\section{The Surface Tension of Gold}

In practice, experimental values are obtained either in the liquid phase, or, at equilibrium with atmosphere, from contact angle measurements. In the former case the high energy values expected from the relation between the cohesive energy and surface tension are found while in the latter, low energy values characteristic of hydrophobic solids are measured.

\section{Liquid Gold Surface Tension}

The surface tension of pure liquid gold has been measured by the hanging and sessile drop methods (for description see(1)), and the experimental results given in the Handbook of Chemistry and Physics (12) are reported in Table I. Experimental values are in agreement with those expected from the breaking of metal bonds.

Solid Gold Surface Tension Around the Melting Point

Extrapolation of the above values leads to the solid $\gamma_{A t}^{s}$ values at the melting point obtained from (12):

$$
\begin{aligned}
& \gamma_{A l u}^{s}=754 \mathrm{~mJ} / \mathrm{m}^{2} \text { or } 731 \mathrm{~mJ} / \mathrm{m}^{2} \text { in vacuum } \\
& \gamma_{A l u}^{s}=1130 \mathrm{~mJ} / \mathrm{m}^{2} \text { in helium }
\end{aligned}
$$

A.H. Cottrell (13) quotes the value $\gamma_{A t}^{s}=1400 \mathrm{~mJ} / \mathrm{m}^{2}$ in helium at $1030^{\circ} \mathrm{C}$ while direct measurement by A. Grosse (14) yields

$$
\gamma_{A_{u}}^{s}=1136 \mathrm{~mJ} / \mathrm{m}^{2} \text { at the melting point }
$$

which is the value generally accepted and which compares favourably with the value of $1124 \mathrm{~mJ} / \mathrm{m}^{2}$ calculated by H. Schonhorn (15). At room temperature the surface tension value should be of the same order of magnitude, part of it corresponding to metallic bonds and part to dispersive interactions. 
Gold Surface Tension from Wettability Studies

The values of the contact angles of polar liquids on 'clean' gold are unexpectedly high for a metal. Over a gold surface cleaned by water condensation for $3650 \mathrm{~h}, \mathrm{Erb}$ (16) found the contact angle $\theta_{\mathrm{H}_{2} \mathrm{O}}$ of water to be

$$
40^{\circ}<\theta_{\mathrm{H}_{2} \mathrm{O}}<79.5^{\circ}
$$

These values are characteristic of a hydrophobic surface and of surface tension values of some $45 \mathrm{~mJ} / \mathrm{m}^{2}$, and are reproducible.

Recent measurements (17) under carefully controlled clean conditions such as are used in the microelectronics industry showed that contamination does not play a role unless it is atmospheric (possibly carbon monoxide or dioxide). New developments in the method of calculation of the surface tension (from the contact angle) all lead to a low surface energy value of gold around $40 \mathrm{~mJ} / \mathrm{m}^{2}$ (17) with a critical surface tension $\gamma_{c}=35 \mathrm{~mJ} / \mathrm{m}^{2}$ independent of the cleaning conditions $(17,18)$.

\section{Energy of Dispersive Interactions of Gold Surfaces}

Given that gold has no superficial oxide layer and interacts through dispersive interactions with water, Thelen (19) deduced from the experimental value of contact angle $\theta_{\mathrm{H}_{2} \mathrm{O}}=65.5^{\circ}$ and from equations 12 and 14 that

$$
\gamma_{s}^{d}=126 \mathrm{~mJ} / \mathrm{m}^{2}
$$

This value fitted both Fowke's (20) calculation of the $\gamma_{s}^{d}$ value from pair interaction potential

$$
60 \mathrm{~mJ} / \mathrm{m}^{2}<\gamma_{s}<120 \mathrm{~mJ} / \mathrm{m}^{2}
$$

and Schonhorn's results (15), showing that for most metals

$$
\frac{\mathscr{C}_{\mathrm{C}}^{d}}{\mathscr{Y}_{L}}=0.07
$$

which from Grosse's value $\gamma_{L}^{\prime}=1336 \mathrm{~mJ} / \mathrm{m}^{2}$ leads to

$$
\gamma_{s}^{d^{\prime}}=121.6 \mathrm{~mJ} / \mathrm{m}^{2}
$$

Actually, if one considers a series of contact angle values for various polar liquids, the agreement between Thelen's results and calculated value seem a coincidence. In the author's laboratory the same value as Thelen's was found for the contact angle of water over the various gold surfaces studied, but for both methylene iodide and bromonaphthalene we found (Table II) that:

$$
\gamma_{s}^{l} \sim 42 \mathrm{~mJ} / \mathrm{m}^{2}
$$

and from the contact angle of various liquids (Table III), the Thelen hypothesis that $W_{a} \sim W_{a} d$ gives

$$
\gamma_{s}^{d}=60 \mathrm{~mJ} / \mathrm{m}^{2}
$$

The Surface Energy of Gold due to Polar Interactions

From the values presented in Table III it is clear that the dispersive interactions cannot account for the whole of the energy of adhesion and that there exists a definite (although small) polar interaction of gold with polar liquids. From measurements obtained by the author and his colleagues using the - not entirely satisfactory but

\begin{tabular}{|c|c|c|c|c|}
\hline Liquid & $\begin{array}{c}\gamma_{b^{\prime}} \\
m m^{2}\end{array}$ & $\mathrm{~mJ} / \mathrm{m}^{2}$ & $\begin{array}{c}\mathrm{W}_{\mathrm{d}}= \\
\gamma_{\mathrm{L}}(1+\operatorname{Cos} \theta) \\
\mathrm{mJ} / \mathrm{m}^{2}\end{array}$ & $\begin{array}{c}\gamma_{s}^{d}=W^{2} / 4 \gamma_{i}^{d}, \\
m J / m^{2}\end{array}$ \\
\hline D.M.S.O. & 45 & 35 & 84 & 50 \\
\hline Triethylene Glycol & 47.4 & 29.5 & 86 & 63 \\
\hline Formamide & 58 & $39.5 \pm 7$ & 97.5 & 60 \\
\hline Glycerol & 65.7 & $37 \pm 4$ & 97 & 63.5 \\
\hline Water & 72 & 22 & 104 & 123 \\
\hline
\end{tabular}

Table II

The Dispersive Interaction of Gold with Non-polar Organic Liquids

\begin{tabular}{c|c|c}
\hline Test liquids & $\begin{array}{c}\text { Contact angle, } \\
\theta^{\circ}\end{array}$ & $\begin{array}{c}\text { Dispersive surface } \\
\text { energy } \gamma_{\mathrm{s}}^{\mathrm{d}}, \mathrm{mJ} / \mathrm{m}^{2}\end{array}$ \\
\hline $\begin{array}{c}\text { Methylene lodide } \\
\gamma_{\mathrm{L}}=50.8\end{array}$ & $31-40$ & $42 \pm 2$ \\
Bromo Naphthalene & 22 & $41.5 \pm 1$ \\
$\gamma_{\mathrm{L}}=44.6$ & & \\
& & \\
& & \\
& &
\end{tabular}

Value of the Dispersive Portion of Gold Surface Energy $\left(\gamma_{s}^{d}\right)$ Assuming a Purely Dispersive Solid Surface

quite efficient - approach of Kaeble we find (Table IV)

$$
\gamma_{s}^{p}=5 \mathrm{~mJ} / \mathrm{m}^{2}
$$

\section{Various Gold Surfaces}

The work reported upon thus far concerns evaporated films of gold. In general, gold is not used in the form of a pure metal but either lightly alloyed or electroplated. We have compared the wettability of pure flat polished gold, alumina polished 18ct goldsilver, $18 \mathrm{ct}$ gold-cadmium electrodeposits, and $22 \mathrm{ct}$ gold-silver electrodeposits, with that of evaporated layers (17).

\section{Table IV}

Surface Tension of Solid Gold $\left(\gamma_{s}^{\text {Au }}\right)$ in $\mathrm{mJ} / \mathrm{m}^{2}$ for the Dispersive and Polar Portions

\begin{tabular}{c|c|c|l}
\hline$\gamma_{s}^{\text {Au }}$ & $\gamma_{s}^{\text {Au,d }}$ & $\gamma_{s}^{\text {Aw,p }}$ & Conditions \\
\hline 1100 & 130 & 1000 & $\begin{array}{l}\text { At the melting point } \\
\text { Pair interaction potential (calculated) } \\
-\end{array}$ \\
$\begin{array}{c}\text { Water contact angle assuming only } \\
\text { dispersive interactions }\end{array}$ \\
126 & - & 0 & $\begin{array}{l}\text { Methylene lodide contact angle } \\
\text { Polar liquids contact angle }\end{array}$ \\
- & $40 \pm 5$ & - & \\
$45 \pm 5$ & $40 \pm 5$ & $5 \pm 5$ &
\end{tabular}


Whereas the results of the contact angle measurement show a 10 per cent variation and more for the contact angle of water, the corresponding surface free energy is in the 37 to $45 \mathrm{~mJ} / \mathrm{m}^{2}$ range. Alumina polishing does not produce water spreading. The values reported in Table V indicate that the results discussed above are valid for these various surfaces also, and is in agreement with other work published for different gold surfaces (21).

\section{Dependence of Surface Energy on Surface Treatment}

Despite the relative uncertainty of the value of the contact angle, $\theta_{\mathrm{H}_{2} \mathrm{O}}$, of water over gold under atmospheric conditions $\left(40^{\circ}<\theta_{\mathrm{H}_{2} \mathrm{O}}<80^{\circ}\right)$ it is clear that there is no dependence of the average value upon the surface cleaning conditions employed in different laboratories $(17,19)$.

None of the usual methods used to obtain clean surfaces, free of organic contaminants, such as

- heating in air at $500^{\circ} \mathrm{C}(2 \mathrm{I})$

- exposure to ultraviolet + ozone oxidation (5)

- degassing in vacuum at $500^{\circ} \mathrm{C}(21)$

- heating in hydrogen (or inert gas) at $1000^{\circ} \mathrm{C}(22)$

- plasma etching in oxygen (21)

could change the contact angle value of water on gold although these methods are effective on other metals such as stainless steel.

\section{Hydrophobicity of Gold from Electrochemical Studies}

The data obtained from electrode/electrolyte interfaces may be used to characterize the interactions of water on gold (23). It is thought that a hydrophilic surface will promote the formation of water dipoles and modify the surface potential. The surface potential of the electrode is related to its work function and the surface potential of the water $\left(g_{\text {aipole }}\right)$. Recent measurements give $g_{\text {dipole }}=0.01 \mathrm{~V}$ on an electrode made contamination-free by repetitive anodic cycling. This value corresponds to a hydrophobic surface. Furthermore the inner layer capacity value at the point of zero charge is characteristic of the 'less hydrophilic' metal (24). Recent electrochemical studies confirm the hydrophobic character of gold (23).

\section{Table VI}

\section{Experimental Conditions Applied to Observe a Hydrophilic Gold Surface (Metastable State of Duration 10 mins in the Atmosphere)}

\begin{tabular}{l|c}
\hline \multicolumn{1}{c|}{ Method } & References \\
\hline Heating to white hot and rapid cooling in an inert gas & 22 \\
Melting in a soft hydrogen flame & 27 \\
Evaporation in U.H.V. argon bleed and immediate drop & \\
deposition & 21,26 \\
Cooling from the melt in air & 28 \\
Heating at $500^{\circ} \mathrm{C}$ and quenching in deionized water & 21 \\
Etching for 2 in aqua regia followed by deionized & \\
water rinse and immediate testing & 21
\end{tabular}

As recalled byJ. Westwater (21), this hydrophobic character has been the subject of much controversy in the literature. Some authors state that a gold surface is hydrophilic and organic contaminants change it into a hydrophobic state while others insist that wetting is observed only over oxidized surfaces. It is now well established (21, 26) that wetting of gold by water may be observed. We have presented the experimental conditions that are found in the literature in Table VI; it is striking that wetting is observed shortly after quenching or etching the outer gold layer for a short period of time. It is important to note that Schneegans (28) has shown that wetting could be observed also by quenching in air, and found no dependence on the surface carbon content.

It is thought by the author and his colleagues that the above results show that wettable gold is in a metastable state and that this should be considered in conjunction with the observation of Feders (29), who reports that quenched gold surfaces are unreconstructed (that is they have the same properties as the bulk), and that this metastable state shortly rearranges and the surface bonds shorten. This could provide another explanation of the hydrophobicity of the gold surface.
Table V

\section{Comparison of Wettability of Various Gold Surfaces - Values of $\cos \theta$}

\begin{tabular}{l|c|c|c}
\hline Liquid & $\begin{array}{c}\text { Evaporated } \\
\text { gold }\end{array}$ & $\begin{array}{c}\text { Solid gold alloy } \\
\text { (18 ct.) }\end{array}$ & $\begin{array}{c}\text { Gold plate } \\
\text { (22 ct.) }\end{array}$ \\
\hline Water & $0.36-0.52$ & $0.43-0.75$ & $0.51-0.68$ \\
$\mathrm{NaOH}$ & - & - & $0.61-0.68$ \\
Glycerol & $0.43-0.54$ & $0.59-0.65$ & $0.21-0.37$ \\
Formamide & $0.65-0.70$ & $0.52-0.6$ & $0.73-0.81$ \\
$\mathrm{CH}_{2} \mathrm{I}_{2}$ & $0.76-0.86$ & $0.6-0.7$ & $0.70-0.80$ \\
T.E.G. & $0.78-0.84$ & $0.7-0.97$ & $0.69-0.76$ \\
P.G. & $0.86-0.93$ & $0.78-0.85$ & $0.83-0.91$ \\
D.M.F. & $0.94-0.98$ & 1 & 0.89
\end{tabular}

It is also known (30) that whereas atoms on reconstructed surfaces have shorter bond lengths than in the bulk, adsorption will increase these to nearly the bulk value. By speculating somewhat and pursuing the above parallel, it could be imagined that the reconstructed gold surface is hydrophobic while the unreconstructed one is not, and that adhesive adsorption over the hydrophobic surface will change it. That idea accounts for the experimental 'displacement of contamination' by epoxy compounds observed by Andrews (5). 


\section{Adhesion Energy on Gold - Summary}

The different solutions for either the force of rupture or the energy of separation (Part I) have been presented and it has been shown that they are a function of the adhesion energy, $W_{a}$. Ways of calculating values of $W_{a}$ have been explored. Thus it was expressed as a function of the surface energy $\gamma_{s}$, which, being experimentally available, should have led us to a way of predicting adhesion to gold.

However, the experimental value is unexpectedly low and we have encountered the old question of why gold appears hydrophobic when it is expected that the clean surface of a metal should be wettable. Our review of the literature leads us to discuss the validity of the explanation that this occurs through gold surface contamination. Thus instead of being able to predict the adhesion to gold, we can only say that either the gold has a high energy surface in which case adherence to it will be comparable to that of other surfaces, or it has a low energy surface in which case the force of adherence will be one half of that of other high energy surfaces.

The measurement of the strength of adhesive joints to gold should provide some answer to this question.

\section{The Strength of Adhesive Joints to Gold}

At Asulab we hàve measured the lap shear and the peel resistance (via a wedge test) while the work by Andrews (5) was concerned with the peel resistance.

Joints of brass, steel, aluminium and stainless steel, considered to be representative of high energy surfaces, were compared to those of gold.

\section{Lap Shear Tests}

The experimental joints were made of two rectangular plates of the metal or gold plated brass which overlapped each other by 10 $\mathrm{mm}^{2}$ (Figure 2a) joined by adhesives. The joint thickness was of the order of $0.1 \pm 0.02 \mathrm{~mm}$. The assembly was pulled at a rate of 10 $\mathrm{mm} / \mathrm{min}$. Interfacial fracture occurred with room curing epoxies. The force of adherence was shown to have the same value over all

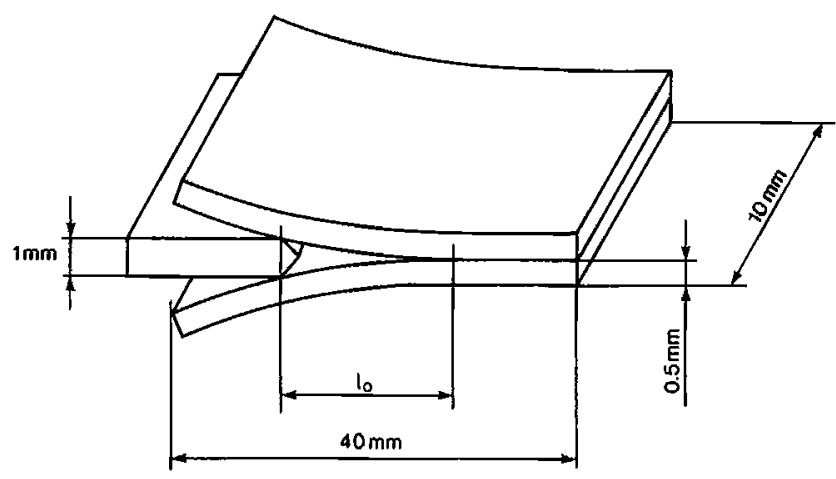

metals tested (Table VII) with the same adhesive, indicating that the energy of adhesion reaches the same value.

\section{Peel Tests}

Andrews studied the peel strength of epoxies over gold and stainless steel under different conditions. From equation 16 the energy of adhesion was calculated. It was found that energy of adhesion does not vary significantly irrespective of whether gold is only solvent cleaned or passed under ozone and ultraviolet, while the surface tension showed a slight variation. This led Andrews to suggest that 'epoxy resins purge the surface of hydrocarbon contaminants'.

The energies of adhesion of epoxy over solvent cleaned gold and chemically etched stainless steel are equal (Table VIII) except in the case of resin 1 which appears to form 'primary' bonds with stainless steel and not with gold.

Our results from the wedge test (Figure $2 \mathrm{~b}$ ) initial fracture show that both stainless steel and gold joints have similar peel strengths. In general, the initial energy of adhesion over gold is equal to that with stainless steel, however some resins form joints of higher strength with the latter than with the former. The hydrophobic character of gold disappears in adhesive joints, (at least initially).

Table VII

\section{Comparison of the Joint Strengths Between Different Metals and Gold}

\begin{tabular}{l|c|c}
\hline Substrate & $\begin{array}{c}\text { Shear strength, } \\
\mathrm{N} / \mathrm{mm}^{2}\end{array}$ & Peel strength ${ }^{*}$ \\
\hline Brass & $40 \pm 5$ & - \\
Stainless Steel & $38 \pm 6$ & $18 \pm 2$ \\
Steel & $38_{ \pm} 6$ & - \\
Aluminium & $38 \pm 5$ & $15 \pm 2$ \\
Gold & $37 \pm 5$ & $16 \pm 2$ \\
"mmof fracture in the wedge test. The length of the fracture, $1_{0}$, is related to the
\end{tabular}
peel strength, $P(\mathrm{~N} / \mathrm{mm})$, by $\mathrm{P}=3.12 \times 10^{4} 1_{0}^{3} \mathrm{~N} / \mathrm{mm}$; if $1_{0}$ is in $\mathrm{mm}$

Fig. 2 Geometry of the test specimens used to study the behaviour of adhesive joints to gold

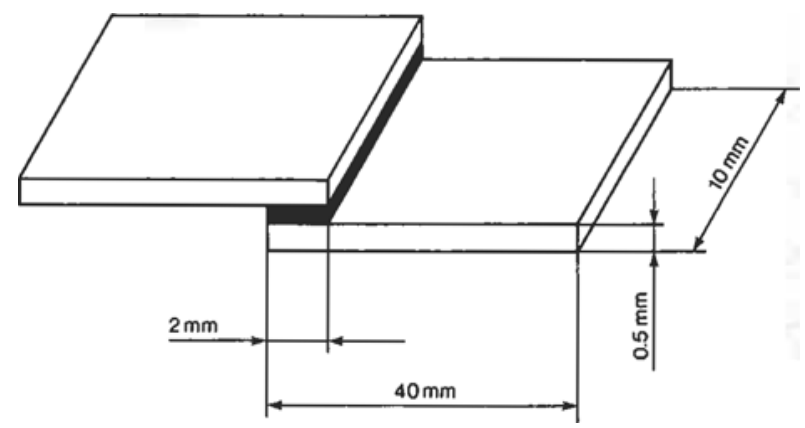




\section{Environmental Resistance}

One critical property of adhesive joints is the resistance of them to the environment, mainly to water. As gold does not corrode one may think that the durability of joints of this metal would be optimum. Comparison of strength of adhesive joints between brass and gold after exposure to a humid atmosphere indicates that this is so, but comparison of gold with stainless stecl evaluated with the wedge test indicates that the gold joint shows a higher sensitivity to moisture - Table IX. (Adhesive joints to gold have also been shown to be very sensitive to dimethylformamide). It will be noticed that in Table IX the one component epoxy resin which weakens slightly when it joins gold substrates shows no sensitivity to moisture if used with stainless steel. In every case the rupture of the humid joint is adhesive.

Comparison of adhesive joints to gold and other metals does not

Table VIII

The Energy of Adhesion of Some Epoxy Resins on Gold and Steel After Different Modes of Cleaning. After (5)

\begin{tabular}{c|l|c|c}
\hline Resin & Mode of Cleaning & Gold & Steel \\
\hline 1 & Solvent & 715 & \\
2 & Chemical etching & & 715 \\
& Solvent & 800 & \\
2 & Chemical etching & & 700 \\
3 & U.V. + ozone & 600 & 680 \\
& Solvent & 1350 & 7820
\end{tabular}

indicate the presence of a substantially lower surface energy - if it is indeed lower at all. Initial tensile and shear strength are comparable while the peel strength is sometimes weaker.

The higher sensitivity of the adhesive joint to gold is not easily explained by the preceding considerations.

\section{Conclusions}

In the first part we recalled that the adherence force, $F$, between two solid bodies $\mathrm{A}$ and $\mathrm{B}$ of unit surface is related to the energy of adhesion $W_{A}$. Although the relation $F_{A}=f(v, c, T) W_{A}$ is not always known it permits a comparison between various experiments. $W_{\Lambda}$ is a function of the surface free energy $\gamma_{s}$, thus one may write:

$$
\mathrm{F}=\varphi(\mathrm{v}, \mathrm{T}, \mathrm{c})\left(\gamma_{\mathrm{s}}\right)
$$

and the knowledge of $\gamma_{s}$ should also allow for the prediction of the adherence force. Gold surface energy is found to be either high or low with the dispersive contribution $\gamma_{s}^{\prime}$ being 45 or $126 \mathrm{~mJ} / \mathrm{m}^{2}$. The latter corresponds better to the initial strength of the adhesive joints. The common (and convenient) explanation of these two values is that a 'clean' gold surface has a high energy but that it is very easily contaminated by adsorbed hydrocarbons which produce a low energy surface layer. The resistance of the proposed contamination to cleaning is unusual. Neither plasma etching nor dull red heating, nor 3500 hours of cleaning in water could remove it. Hydrophilic gold surfaces are obtained for a short time either by quenching from very high temperature or by physical or chemical etching (the latter in aqua regia), and observing the surface immediately. The wettable gold surface is clearly a metastable state under atmospheric conditions. From available experimental results, contamination by

Table IX

Results of Wedge Crack Test in Humid Environment $\left(40^{\circ} \mathrm{C}, 90 \%\right.$ Relative Humidity) Comparison of the Stability of Joints Made Between Stainless Steel or Gold and Exposed to a Tropical Atmosphere

\begin{tabular}{|c|c|c|c|c|c|c|}
\hline \multirow{2}{*}{$\begin{array}{l}\text { Metal } \\
\text { Adhesive }\end{array}$} & \multicolumn{3}{|c|}{ Gold } & \multicolumn{3}{|c|}{ Stainless Steel } \\
\hline & $\begin{array}{l}\mathrm{L}_{0}, \\
\mathrm{~mm}\end{array}$ & $\begin{array}{l}\mathrm{L}_{24}{ }^{* *} \\
\mathrm{~mm}\end{array}$ & $\begin{array}{l}\Delta_{\mathrm{L}} \dagger \\
\mathrm{mm}\end{array}$ & $\begin{array}{l}\mathrm{L}_{0}{ }^{*} \\
\mathrm{~mm}\end{array}$ & $\begin{array}{l}\mathrm{L}_{24}{ }^{* *} \\
\mathrm{~mm}\end{array}$ & $\begin{array}{l}\Delta_{\mathrm{L}} \dagger \\
\mathrm{mm}\end{array}$ \\
\hline $\begin{array}{l}\text { 828/T.E.T.A. } \\
\text { Modified DGEBA }\end{array}$ & 16 & 26.5 & 10.5 & 16.5 & 20.5 & 4 \\
\hline $\begin{array}{l}\text { one component } \\
\text { Epoxide resin }\end{array}$ & 14 & 20.5 & 6.5 & 11.5 & 14.5 & 3 \\
\hline $\begin{array}{l}\text { one component } \\
\text { Flexibilized }\end{array}$ & $\begin{array}{c}15 \\
205\end{array}$ & $\begin{array}{c}19.5 \\
37\end{array}$ & $\begin{array}{c}4.5 \\
16.5\end{array}$ & $\begin{array}{l}10 \\
20\end{array}$ & $\begin{array}{c}10 \\
305\end{array}$ & $\begin{array}{c}0 \\
105\end{array}$ \\
\hline
\end{tabular}

The extension of the initial crack is indicative of the sensitivity of the joint to mixture - each value is an average of seven measurements

$" L_{0}=$ initial length of the crack after introduction of the wedge

$+\Delta L=L_{24}-L_{0}$ 
hydrocarbon may not be the best explanation of the two surface energy states of a gold surface.

Recent studies of the surface of solids show that a gold surface may exist either with its bulk atomic properties (unreconstructed surface) or with shorter (reconstructed) atom bond lengths at the surface. This could be the reason for the apparent experimental duality which exists, with the unreconstructed surfaces behaving in a hydrophylic manner while the reconstructed surfaces show hydrophobic behaviour.

The question of whether gold is hydrophobic or hydrophilichas engineering consequences. One of these is the dropwise condensation of water vapour in heat exchanges.

Electrodeposited or evaporated gold surfaces of thickness greater than $200 \mathrm{~nm}$, unlike those of steel or copper, show dropwise condensation. J.W. Westwater reviewed the state of the art in this journal (21), and commented in the following terms: 'dropwise condensation will have commercial application as soon as the troublesome problem of how to main tain it for a long time period is solved. Gold may offer the solution or indicate how to obtain the solution'.

Either gold has a unique behaviour towards organic contaminants or gold surfaces exist in two energetic states. Further work should aim towards obtaining experimental evidence for one or the other explanation found in the current literature.

Besides the above application it is of great interest to the jewellery industry that reliable adhesive joints to gold be developed, and achieving this goal may change much of the present art and technology involved in the working of jewellery alloys.

\section{References}

1 A.W. Adamson, 'Physical Chemistry of Surfaces', 3rd Edition, Wiley, 1976

2 D. Maugis, 'Le Vide' 186, 1977, pp. 1-19, and in 'Microscopic Aspects of Adhesion and Lubrication', edited by J.M. Georges, Elsevier, 1982

3 F.M. Fowkes, in 'Treatise on Adhesion and Adhesives', Vol. 1, edited by R.L. Patrick, M. Dekker, 1966

4 A.A. Griffith, Phil. Trans. Roy. Soc., 1920, A221, 163-198

5 E.H. Andrews, Org. Coat. Appl. Polym. Sci. Proc, 1982, 47, 328-331

6 D. Maugis and M. Barquins, J. Phys. D. Appl. Phys., 1978, 77, 1989-2023

7 J. Schultz and A.N. Gent, J. Chem. Phys., 1973, 70, 708

8 A. Gent, Rubber Technol., 1947, 47, 202

9 F.M. Fowkes, Adv. Chem. Ser., 1964, 43, 99

10 D.H. Kaelble, 'Physical Chemistry of Adhesion', Wiley, 1971

11 F.M. Fowkes, in 'Microscopic Aspects of Adhesion and Lubrication', edited by J.M. Georges, Elsevier, 1982

12 'Handbook of Chemistry and Physics', 60th Edition, CRC, 1979

13 A.H. Cottrell, 'The Mechanical Properties of Matter', J. Wiley, 1964

14 A.A.V. Grosse, J. Inorg. Nucl. Chem, 1964, 26, 1349

15 H. Schonhorn, J. Phys. Chem., 1967, 71, 4578

16 R.A. Erb, J. Phys. Chem., 1965, 69, 1307

$17 \mathrm{~J}$. Cognard and C. Boichard, in 'Addhesion', Vol. 8, edited by K.W. Allen, Elsevier Applied Science, pp. 169-193, 1983

18 K.W. Bewig and W.A. Zisman, J. Phys. Chem., 1964, 68, 1804

19 E. Thelen, J. Phys. Chem., 1967, 71, 1946-1948

20 F.M. Fowkes, Ind. Eng, Chem., 1964, 56, 40

21 J.W. Westwater, Gola Bull., 1981, 14, (3), 95-101

22 K.W. Bewig and W.A. Zisman, J. Phys. Chem., 1965, 69, 4238

23 G. Valette, J. Electroanal. Chem., 1983, 139, 285-302

24 J. Clavillierand C. Neuyen van Huong, J. Electroanal. Chem, 1973, 41, 193. (In the original work it was stated that gold was the most hydrophobic metal. In a recent discussion with J. Clavillier he advised it to be expressed as the "less hydrophilic metal')

25 M.L. White, J. Phys. Chem., 1964, 68, 3083-3085

26 T. Smich, J. Coll. Int. Soi., 1980, 75, 51-55

27 G.L. Gaines Jr., J. Coll. Int. Sci., 1981, 79, 295

28 M. Schnecgans and E. Mencel, J. Coll. Int. Sci, 1982, 88, 97-99

29 R. Feders, Surf. Sci, 1977, 68, 229-235

30 M.A. Van Hove, Surf. Sci., 1979, 81, 1-7

\section{Electropolishing of Gold}

One of the aspects of gold working which has always been open to improvement, in particular with regard to the large jewellery manufacturing industry, is that of surface finishing of the gold piece. Mechanical finishing (polishing) is time consuming and requires skilled personnel. Electrolytic polishing in which gold is removed anodically in a solution in a controlled manner to give a bright finish has been used but is susceptible to a number of obstacles, chief of which is the difficulty of achieving a consistent finish on alloys of different caratage and containing different alloying elements. Most electropolishing which is carried out on gold alloys is effected in toxic cyanide solutions, which means that special precautions are needed to ensure safety.

Recent work reported by J. Verlinden, J.P. Celis and J.R. Roos ('Passivity of Metals and Semiconductors', edited by M. Froment, Elsevier Science Publishers, Amsterdam, 1984) on the passivationdepassivation behaviour of gold in a hydrochloric acid-glycerol solution for the purpose of thinning electrodeposited gold samples for TEM examination, extends our understanding of the subject and, if applicable to gold alloys, might well have significant practical applications in other areas.

Previous work on the anodic behaviour of gold in hydrochloric acid solutions had shown that when the gold electrode was held in acertain potential range the current oscillated periodically and this was thought to be due to two competing processes viz. the formation of $\mathrm{Au}$ (III) oxide at the electrode surface and the redissolution of this oxide by the chloride ions present in the solution. Such behaviour, if controlled, might lead to useful polishing of the gold surface and Verlinden et al. have found that modifying the electrolyte by the addition of glycerol reduced the gold dissolution rate to the extent that this could be achieved.

Pure gold deposits with different morphologies were formed from additive-free cyanide gold plating solutions by varying the cathodic current densities. Anodic polarization runs with these specimens in hydrochloric acid-glycerol (25:75 weight per cent) solutions at room temperature revealed a passivation potential, due to the formation of an $\mathrm{Au}$ (III)oxide film, which was independent of the structure and morphology of the gold surface. At potentials close to that of passivation periodic oscillations of current occurred similar to those previously obtained with unmodified hydrochloric acid solutions, and high quality electropolishing of the gold surface was obtained. The quality of the surface finish appeared to be virtually independent of the initial specimen topography and structure.

Further improved control of the thinning process was achieved by applying a cyclic potential sweep between the active and passive ranges, so controlling the frequency of current oscillations and the times for which the surface was in the active and passive regions.

It will be interesting to see whether these potentially useful results can be extended and applied to practical gold alloys. 